Science of Lifelong Learning

\title{
The Science of Lifelong Learning
}

\section{Alicia M. Goodwill ${ }^{1}$ \& SH Annabel Chen ${ }^{1,2,3,4}$}

${ }^{1}$ Centre for Research and Development in Learning, Nanyang Technological University, Singapore

${ }^{2}$ Psychology, School of Social Sciences, Nanyang Technological University, Singapore

${ }^{3}$ Lee Kong Chian School of Medicine, Nanyang Technological University, Singapore

${ }^{4}$ National Institute of Education, Nanyang Technological University, Singapore

\section{Correspondence:}

Professor SH Annabel Chen

Nanyang Technological University, SHHK 04-19, 48 Nanyang Avenue, Singapore 639818 Tel: (65) 6316-8836 GMT+8h | Fax: (65) 6795-5797 | Email: annabelchen@ ntu.edu.sg

Author acknowledgement: The current manuscript is pre-edited version and will be published in its final form by The United Nations Educational, Scientific and Cultural Organisation Institute for Lifelong Learning (UIL) (in April 2021). 
Science of Lifelong Learning

\begin{abstract}
The impetus for nations to build resilience for rapid changes and uncertainty, and the increasing complexity of challenges has made sustainable development a priority. Lifelong learning holds the key to sustainability in maximizing human potential to address the needs of the future. The development of the science of lifelong learning is emerging and gaining traction through interdisciplinary discourse and research. It has provided a framework to view lifelong learning from cradle to grave with foundations in our understanding of brain development, degeneration, and plasticity ${ }^{l}$. The space for lifelong learning is interactive, lifewide and entrenched in rich social contexts. Thus, the translation of scientific knowledge (including neuroscience) to be consumable by the masses (the learners), and the agents providing knowledge (the educators and parents), will be instrumental in promoting inclusive and participatory processes of knowledge production and sharing. We envision the science of lifelong learning to empower learners from diverse backgrounds and societies to have the capacity to contribute to a learning planet. This chapter provides a brief overview of the current state of the science of lifelong learning. We will showcase some ongoing research on the science of learning at our centre in Singapore and discuss implications of lifelong learning for futures of education, economy, health, and well-being.
\end{abstract}

\footnotetext{
${ }^{1}$ Brain plasticity (or referred to as neuroplasticity) is the capability of the brain to change, adapt and reorganise itself in response to learning, experience, or injury.
} 
Science of Lifelong Learning

\section{Introduction}

The way we live, work, and learn is rapidly evolving to meet the demands of globalisation, digitalisation, and longevity. Lifelong learning is an imperative initiative to maximise human potential across the lifespan and remain at the forefront of these challenges. Learning can take place in formal (e.g., intentional learning for a degree or certificate, in structured settings such as schools or university), non-formal (e.g., intentional learning within an organisational structure to master a skill that can (but not necessary) complement a degree, such as online courses or swimming classes) and informal settings (e.g., experiential learning that can occur in the home, work or community, such as home baking or workplace mentoring). Lifelong learning can be viewed as holistic combination of these experiences, enabling individuals to remain competitive in the workforce, promote personal and social development and active citizenship (Laal and Salamati, 2012).

The professional, societal, and individual benefits from lifelong learning have motivated inquiry into how science, in particular, psychology, social sciences, and neuroscience, can support lifelong learning initiatives to be grounded in knowledge of how the brain processes information for learning over the lifespan. These fields have begun to shed light on the complex interactions of neurobiological, psycho-socio-emotional and lifestyle factors that could facilitate or inhibit learning. To date, the science of learning has predominantly centred on neurodevelopmental and neurodegenerative age-windows, often neglecting learning throughout adulthood. Similarly, this can be observed in the evidence-based research implementation which has focused on formal education, with a scarcity of research evaluated in workplace and other professional settings (Lee, 2017). Considering adults constitute the majority of the current and future workforce, the science of lifelong learning presents an opportunity to direct attention to this population and positively influence the future of education (Knowland and Thomas, 2014). The following sections will discuss the neuro- 
Science of Lifelong Learning

cognitive, psycho-socio-emotional and lifestyle considerations for lifelong learning initiatives and policies. This chapter emphasises the importance of research translation and participation in interdisciplinary collaboration to drive impact in this field and presents some of the successes and challenges from the work being conducted in this area from a Singapore context. Lastly, the chapter will highlight the economic, health and societal implications from investment in lifelong learning research, policies, and practices.

\section{Neurobiological and cognitive profiles over the lifespan}

Over the past two decades, our knowledge of the brain's inherent malleability in response to the environment, termed neuroplasticity or (brain plasticity) ${ }^{1}$ (Pascual-Leone et al., 2005) has been enhanced with contemporary neuroimaging. Structural and functional Magnetic Resonance Imaging (MRI) and cortical mapping have provided insight into the neurophysiological changes involved in cognitive (Delazer et al., 2005) and motor skill acquisition (Buccino et al., 2004, Cohen et al., 1993). Moreover, the integration of neuroscience with cognitive psychology (i.e., cognitive neuroscience) is an evolving field that can support the science of lifelong learning through knowledge of behavioural, brain morphological (or structural) and functional changes that may influence learning at different stages of the lifespan.

Early examples of the relationship between learning and neuroplasticity have come from sensitive periods in childhood and adolescence (Knudsen, 2004). These periods serve as 'windows of opportunity' where the effects of experience on neuroplasticity and adaptive behaviours are particularly strong. Examples include the consolidation of brain networks and behaviour related to forming vision, hearing, motor skills for walking, and affective learning (or emotional development) (Penhune, 2011, Knudsen, 2004). While the traditional view 
suggested neural networks and behaviours become fixed after these age-windows 'close', it is now accepted that there is more flexibility with learning relying strongly on experiential influences rather than purely age (Knudsen, 2004). This finding has prompted future research into use-dependent neuroplasticity, to better understand the interactions between neurobiology, cognition, and life-course experiences on learning.

Several key factors pertaining to cognitive performance can affect learning across the lifespan. These may include (but are not limited to) dynamic changes in cognitive profiles, cognitive transfer and building cognitive reserve. An important consideration for lifelong learning is the nonlinear nature of cognitive profiles over the lifespan. As one moves through childhood, adulthood into later-life, the patterns of performance over a range of different cognitive abilities and domains also shifts. While declines in information processing speed, attention, task-switching and episodic memory typically decline with age (Verhaeghen and Salthouse, 1997), evidence from 'super-agers' who show minimal or no decline in later-life suggest that cognitive decline is not inevitable (Pudas et al., 2013). Adults can maintain or even improve on other cognitive abilities such as semantic memory, which can in turn enhance metacognitive skills required for lifelong learning (Kennedy et al., 2015, Carstensen et al., 2011). Life-course factors such as education, health and wellbeing can also interact with genetics to influence cognitive trajectories (Yaffe et al., 2009, Josefsson et al., 2012, Arenaza-Urquijo et al., 2015). It is also plausible that age-related slowing of processing speed and task-switching is not a direct result of neurodegeneration, rather it could reflect the greater neural effort required for a task as adults prior knowledge and environment becomes increasingly more complex (Ramscar et al., 2014). It is therefore important to consider these trajectories towards harnessing the metacognitive strengths of adults for positive learning outcomes (Hertzog and Dunlosky, 2011). 
Science of Lifelong Learning

There is evidence that the ageing brain is able to continue to undergo neuroplasticity (Boldrini et al., 2018, Larivière et al., 2019, Park and Bischof, 2013). In healthy older adults, behavioural gains that have been achieved through training adds further support to the effectiveness of continued learning into later-life (Park and Bischof, 2011, Teixeira-Santos et al., 2019). One of the measures of success for training, but often difficult to obtain, is the concept of cognitive transfer. This refers to the ability to apply knowledge and skills learnt in one context to a novel learning or problem-solving situation (Steiner, 2001). Near and far transfer are dimensions of transfer, with near transfer referring to applying knowledge to new problems within the same context, and far transfer is to apply what is learnt in an entirely different and novel context. An example of far transfer could be applying what is learnt in a physics class about force and momentum to solve a problem in everyday life in moving furniture. In older adults, studies have reported improvement in trained tasks or near-transfer, however there remains limited evidence for far transfer (Park and Bischof, 2013). Achieving far transfer in ageing could be in part be affected by moderators such as baseline cognitive function, amount of effort and engagement in the task, as well as training dose (TeixeiraSantos et al., 2019).

One of the most notable benefits of education and occupational attainment (Arenaza-Urquijo et al., 2015), including further education in adulthood (Thow et al., 2018) is building a cognitive reserve. The theory of cognitive reserve postulates that there are individual differences in the brain's resilience to maintain cognitive performance, withstanding neurodegenerative changes. For example, natural age-related declines in brain morphology (Mills et al., 2016), and presence of brain pathologies linked to Alzheimer's disease (Ritchie et al., 2015) have been observed in midlife. Despite this, some adults will not go on to develop cognitive decline or disease (Dang et al., 2019). While the mechanisms are not wellunderstood, cognitive reserve is thought to involve compensatory strategies (Reuter-Lorenz 
Science of Lifelong Learning

and Park, 2014) whereby other brain regions may increase activity or take over (compensate) to maintain adequate cognitive performance. Thus, neuroplasticity and learning should not just be considered from a morphological (structural) standpoint, but through a dynamic lens of functional brain changes and behavioural relationships. We argue that the residual benefits of lifelong learning could be protective for cognitive function and allow older adults to remain productive members of the workforce and society.

\section{Psycho-socio-emotional and lifestyle factors implicated in lifelong learning}

Beyond fundamental literacy and numeracy skills (Menon, 2010, Schlaggar and McCandliss, 2007), there has been a shift towards developing $21^{\text {st }}$ century skills in education and socioemotional factors that have implications for lifelong learning. Although the neuroscience underlying these skills is in its infancy, consideration of the imminent pressures for knowledge creation, abstractness and complexity will be pertinent for the future of lifelong learning research (Bereiter and Scardamalia, 2018). Twenty-first century skills can be taught in formal education, but will likely rely on engagement with learning in non-formal and informal settings such as online, the workplace and the home (Yeo, 2008). Not only will the field need to develop methodologies to quantify such learning experiences that are increasingly prevalent in "the wild" (Hutchins, 1995), but should also consider personal, lifestyle and environmental factors that optimise or hinder learning.

The science of lifelong learning encapsulates an individual's neurobiology, health and wellbeing, socioemotional skills and learning environment (Figure 1). These factors can individually and cumulatively fluctuate over the lifespan and influence learning outcomes and cognitive reserve. Knowledge of the bidirectional relationship between learning and wellbeing (Yu et al., 2018, Jenkins and Mostafa, 2015, Jenkins, 2011) may open the door to a 
Science of Lifelong Learning

novel approach for lifelong learning research, considering the competing demands on the adult brain and learning contexts. For example, stress (Vogel and Schwabe, 2016), competing attentional resources (Blanco and Sloutsky, 2019), diet and physical activity (Serra et al., 2020) have all been associated with cognitive performance and learning. The positive influence of prior education, busyness, and large social networks in midlife is also linked to better cognitive abilities in later-life (Festini et al., 2016, Park et al., 2014). Together, this highlights the importance of socioemotional and sociocultural contexts when designing and implementing adult learning policies and practices. 


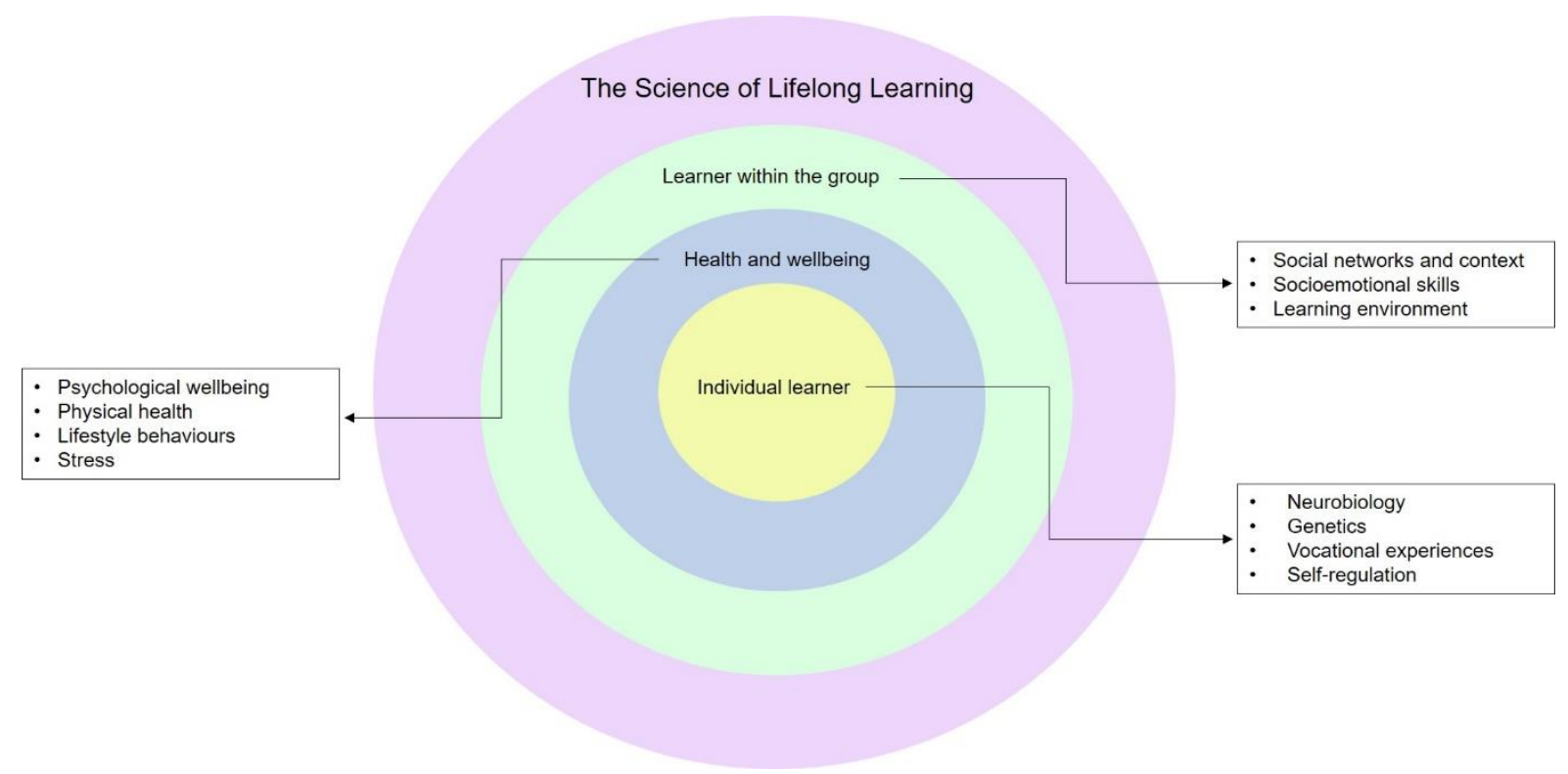

Figure 1 Schematic representation of the biological (individual learner), lifestyle (health and wellbeing) and psycho-socio-emotional and environmental (learner within the group) factors that interact with cognitive processes and learning across the lifespan.

Past education and vocational experience can also shape future learning (Knowles, 1978). Sociocultural experiences have been shown to guide information processing strategies (Park and Gutchess, 2006), highlighting an important area of future research to understand the complexity of the lifelong learner. Moreover, socioemotional, and metacognitive skills continue to evolve into adulthood and have been proposed as critical skills for a future ready and productive workforce (Bughin et al., 2018). The transition into adulthood also encompasses different motivations for engaging in education, and the learning opportunities are vastly different. Adult learning is primarily self-regulated and influenced by different reward processes in the brain (Somerville and Casey, 2010). Therefore, learning motivations may become more intrinsic as the adult brain examines the neural "cost-benefit" trade-off to acquire new knowledge and perform new skills. 
Science of Lifelong Learning

Adult learners form expectations and habits that are entrenched in the brain's neural connections. These prior experiences and knowledge drives future thinking, behaviours and beliefs, and provides an important scaffolding for learning to take place (Knowles, 1978). This aligns with adult learning theories proposing that learning is effective when information is directly relevant to an individual's goals, job requirements and is built upon prior knowledge and experiences (Knowles, 1978). It is also important for learners to be aware of their own preconceptions and beliefs, to understand the interference that these can have with new ways of thinking or content to be learned, and be able to tap into metacognitive skills to make space for new knowledge (Grisold and Kaiser, 2017). The future of lifelong learning research will be required to consider holistically the individual, environmental and social contexts in which learning thrives. This approach can ultimately lead to more effective policies and programs that cultivate future-ready thinkers, learners, and workers.

\section{Knowledge production, translation and sharing}

Considering the diversity of learning environments (Yeo, 2008), knowledge sharing should include educators, parents and the wider community of policy makers, businesses and individuals that together shape the learning experience. Although education is not built upon the traditional medical model of evidence-based practice, the contribution of psychology, social sciences and cognitive neuroscience research to education can already be observed through numerous educational neuroscience initiatives. The goal of this interdisciplinary field is not merely to derive pedagogical practices from neuroscience, but to provide a foundation of which cognitive abilities should be targeted, and how life-course factors can strengthen or hinder learning outcomes (Rose et al., 2013). 
Science of Lifelong Learning

Efforts to narrow the research-to-practice gap and build meaningful partnerships among researchers, educators and the wider community have emerged internationally. Initiatives such as Oxfords Cognitive Neuroscience - Education Forum, University of Cambridge's Centre for Neuroscience in Education, and University of Queensland collaboration with the University of Melbourne's Science of Learning Research Centre, demonstrate a global effort in making this research accessible to the wider community. The Mind, Brain and Education Masters course at Harvard University and the BrainU institute at University of Minnesota have also commenced neuroscience programs for teachers and students, motivating pedagogical shifts towards more student-centred and self-directed learning (Schwartz et al., 2019). Frontiers for Young Minds is further initiative aiming to involve parents and students in the scientific enterprise. The journal invites scholars to translate articles into lay language, which are then reviewed by parents, teachers, and students. This goal is to develop a common dialog that is scientifically accurate and interpretable by the wider community. Whilst many of these initiatives have focused on K-12 learners, there are several centres including the Centre for Research and Development in Learning (CRADLE) at Nanyang Technological University (NTU), Institute for Applied Learning Sciences and Educational Technology (ALSET) at National University Singapore (NUS) and Institute for Adult Learning (IAL), together with Massachusetts Institute of Technology (MIT) Integrated Learning Initiative (MITili) and Science of Learning Institute at John Hopkins, are paving the way for a lifespan approach to the science of learning.

In collaboration with the National Institute of Education (NIE) in Singapore, CRADLE recently developed a Translating Educational Neuroscience Clearinghouse to build dialog and common language between researchers and teaching practitioners (Tham et al., 2019, Tan et al., 2019). In this database, links from neuroscience findings in children with neurodevelopmental conditions are made with behavioural interventions that were translated 
Science of Lifelong Learning

in lay language, and where relevant, ideas were generated about educational implications that could be tested within the classroom. Brain literacy workshops engaging teachers in the scientific enterprise are also underway, with the goal of empowering teachers to meet the needs of diverse learners (Walker et al., 2017). This work at CRADLE is currently being extended to include translational research in adult learners with autism spectrum disorder and attention deficit hyperactivity disorder.

A central theme to the science of learning work at CRADLE and the broader field is the use of neuroimaging with behavioural measures, to provide insights into the brain mechanisms that support cognitive function and learning. Ultimately, the goal is for these findings to help develop strategies to facilitate learning in diverse populations. One of the key challenges in these translation efforts are disparities in testing environments. Cognitive neuroscience findings are typically derived from functional MRI (fMRI) and domain-specific behavioural tests in tightly controlled laboratory environments (Figure 2a). As outlined earlier in this chapter, learning involves complex environmental, lifestyle and social interactions, which poses questions around the impact laboratory research can have in naturalistic settings (Bowers, 2016). To address some of these challenges, functional near-infrared spectroscopy (fNIRS) has been proposed as an alternative neuroimaging tool for use in science of learning research (Brockington et al., 2018). While fNIRS can infer comparable information about brain-behaviour relationships to fMRI (Noah et al., 2015), it's portability, greater tolerance to movement, and lower cost make it a promising tool for use in ecological and social settings, such as the classroom or workplace (Figure 2b). However, future research is still needed to develop protocols for capturing more complex and naturalistic behaviours and quantification of learning in formal and informal settings. 

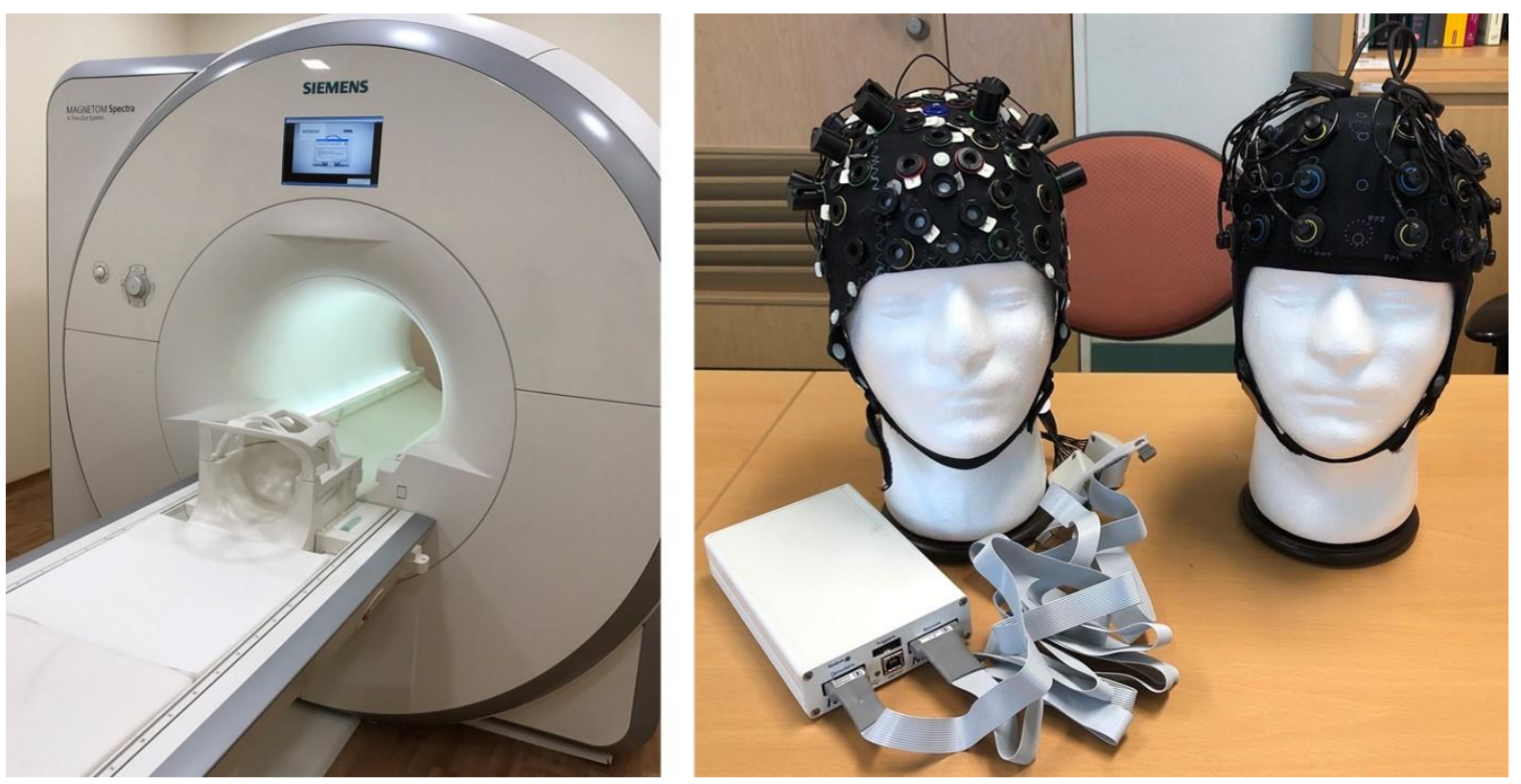

Figure 2 Image of the set-up of a magnetic resonance imaging (MRI) machine (left) and a portable functional near-infrared spectroscopy (fNIRS) device (right).

Another challenge for translation is working within an interdisciplinary team of researchers and practitioners, where there is often a divergence in goals (Ansari et al., 2011).

Neuroscience researchers often resist translating findings into the community with the fear of oversimplification or misinterpretation, while practioners desire direct application to solve real-world learning problems. We can therefore argue that interdisciplinary training (Ansari et al., 2011) or creation of specialised roles in research translation (Howard-Jones, 2010) would be important steps to facilitate inclusion and knowledge sharing for the future of science of lifelong learning. 
Science of Lifelong Learning

\section{Lifelong learning for futures of education, economy, and health}

The demand for lifelong learning will continue to shape educational reform towards continual, intermittent, and informal learning for all age groups. With impending changes to the employment landscape and a trend for more nonlinear career pathways, educational institutions, businesses, and individuals need to take a proactive approach towards becoming lifelong learners. In 2018, the World Economic Forum identified an increasing demand for digital, human care, technological and cross-functional skills. It is predicted that by 2030 , technology will eliminate the need for manual tasks and knowledge-based cognitive skills, requiring more complex thinking, higher-order cognition, digital literacy, and socioemotional skills (Bughin et al., 2018). In a recent example, ASEAN youths were compelled to exercise adaptability and flexibility in response to the COVID-19 health pandemic and subsequent economic downtown, with the majority reporting engagement in reskilling opportunities to enhance digital literacy, creative thinking, or learning new online job skills (World Economic Forum, 2020). For businesses to maintain productivity and avoid recruitment disruption and unemployment, these challenges of the future economic landscape need to be met with an adaptable workforce. This creates a strong impetus for lifelong learning to be emphasised in all age groups.

Within the Singapore landscape, the SkillsFuture movement was developed in 2015 and works with Institutes of Higher Learning (IHL) to incorporate more modular and efficient modes of learning, emphasising real-world problems and applications. In preparation for workplace learning, which is primarily informal and self-driven in nature (Yeo, 2008), IHL's are incorporating self-directed learning into curriculum, increasing preparedness for problem solving, thinking deeply and creatively, whilst also helping students appreciate the value of continued learning beyond formal education. These policies continue to work towards 
Science of Lifelong Learning

balancing the sociocultural expectations of formal certification and grading, with vocational training that encourages critical thinking, creativity, curiosity and being able to adapt and handle workplace diversity (Tan, 2017).

Adult learning efforts in Singapore have leveraged data from learning analytics, social psychology and science of learning to developing scalable interventions such as 'bite-size' and 'just-in-time' learning. The development and uptake of these bite-size learning modules evolved through our understanding of limited cognitive and time resources in a working adult life. These strategies reflect the structural conditions of labour markets with increased pressure for divided attentional resources and task-switching, whereby bite-size learning may improve productivity and performance. One example from the National Trade Union Congress' (NTUC) Employment and Employability Institute (e2i) is the Uleap (Learning Enabled through Active Participation) application. This mobile application provides short modules related to workplace skills such as cloud computing, cybersecurity, and conflict management. The application also reinforces adult learning theory of effective learning that is linked to work skills or real-life responsibilities (Knowles, 1978).

In addition to the revolution of labour markets and job competition, longevity is a global challenge in which lifelong learning could preserve productivity and wellbeing among an ageing workforce and population (Narushima et al., 2018). In turn, retention of older adults in the workforce promotes cognitive engagement, learning opportunities and social inclusion that could further prevent cognitive decline (Thow et al., 2018, Foubert-Samier et al., 2010). Lifelong learning in the form of non-formal learning has been shown to promote psychological wellbeing (Åberg, 2016, Narushima et al., 2018), which is also associated with better cognitive performance in later-life (Nakanishi et al., 2019). There is mounting research to support education and social engagement in midlife having stronger protective effects on 
Science of Lifelong Learning

cognition in later-life (Park and Festini, 2017, Park, 2019). Overall, this reinforces the need for individuals and businesses to engage in lifelong learning, to improve productivity, decrease absenteeism and early retirement, and promote presentism (Sweeny, 2015, Rasmussen, 2015). Subsequently, this would also result in reduced healthcare utilisation and the fiscal burden of age-related disease on the healthcare system (Ton et al., 2017).

\section{Conclusion}

The rapid advancements in technology, globalisation and longevity should be met with an adaptable and flexible community. Lifelong learning will be instrumental in preparing for these changes and cultivating a future ready society that positively shifts the future of education, health, and wellbeing. Interdisciplinary research integrating knowledge from learning sciences with psychology, social sciences, and cognitive neuroscience should be considered in tandem to inform lifelong learning policies and practices. Importantly, opensource data platforms that promote knowledge sharing, accessibility and inclusivity among

educators, businesses, policy makers, individuals and their communities are fundamental for the future of the science of lifelong learning. 
Science of Lifelong Learning

\section{References}

Åberg, P. 2016. Non-formal learning and well-being among older adults: Links between participation in Swedish study circles, feelings of well-being and social aspects of learning. Educational Gerontology, 42.

Ansari, D., Coch, D. and De Smedt, B. 2011. Connecting education and cognitive neuroscience: Where will the journey take us? Educational Philosophy and Theory, 43(1), pp. $37-42$.

Arenaza-Urquijo, E. M., Wirth, M. and Chételat, G. 2015. Cognitive reserve and lifestyle: Moving towards preclinical Alzheimer's disease. Frontiers in Aging Neuroscience, 7, p. 134.

Bereiter, C. and Scardamalia, M. 2018. Fixing humpty dumpty: Putting higher order skills and knowledge together again. Theory of teaching and thinking: International perspectives. London: Routledge.

Blanco, N. J. and Sloutsky, V. M. 2019. Adaptive flexibility in category learning? Young children exhibit smaller costs of selective attention than adults. Developmental Psychology, 55(10), pp. 2060-2076.

Boldrini, M., Fulmore, C. A., Tartt, A. N., Simeon, L. R., Pavlova, I., Poposka, V., Rosoklija, G. B., Stankov, A., Arango, V., Dwork, A. J., Hen, R. and Mann, J. J. 2018. Human hippocampal neurogenesis persists throughout aging. Cell Stem Cell, 22(4), pp. 589-599.

Bowers, J. S. 2016. The practical and principled problems with educational neuroscience. Psychological Review, 123(5), pp. 600-612. 
Science of Lifelong Learning

Brockington, G., Balardin, J. B., Zimeo Morais, G. A., Malheiros, A., Lent, R., Moura, L. M. and Sato, J. R. 2018. From the laboratory to the classroom: The potential of functional nearinfrared spectroscopy in educational neuroscience. Frontiers in Psychology, 9, pp. 1840.

Buccino, G., Vogt, S., Ritzl, A., Fink, G. R., Zilles, K., Freund, H.-J. \& Rizzolatti, G. 2004. Neural circuits underlying imitation learning of hand actions: An event-related fmri study. Neuron, 42(2), pp. 323-334.

Bughin, J. Hazan, E. Lund, S. Dahlström, P, Wiesinger, A. and Subramaniam, A. 2018. Skill shift: Automation and the future of the workforce. McKinsey Global Institute. Available at https://www.mckinsey.com/featured-insights/future-of-work/skill-shift-automation-and-thefuture-of-the-workforce [Accessed 15 August 2020].

Carstensen, L. L., Turan, B., Scheibe, S., Ram, N., Ersner-Hershfield, H., Samanez-Larkin, G. R., Brooks, K. P. and Nesselroade, J. R. 2011. Emotional experience improves with age: Evidence based on over 10 years of experience sampling. Psychology and Aging, 26(1), pp. 21-33.

Cohen, L. G., Brasil-Neto, J. P., Pascual-Leone, A. and Hallett, M. 1993. Plasticity of cortical motor output organization following deafferentation, cerebral lesions, and skill acquisition. Advances in Neurology, 63, pp. 187-200.

Dang, C., Harrington, K. D., Lim, Y. Y., Ames, D., Hassenstab, J., Laws, S. M., Yassi, N., Hickey, M., Rainey-Smith, S. R., Robertson, J., Rowe, C. C., Sohrabi, H. R., Salvado, O., Weinborn, M., Villemagne, V. L., Masters, C. L. and Maruff, P. 2019. Superior memory reduces 8-year risk of mild cognitive impairment and dementia but not amyloid $\beta$-associated cognitive decline in older adults. Archives of Clinical Neuropsychology, 34(5), pp. 585-598. 
Science of Lifelong Learning

Delazer, M., Ischebeck, A., Domahs, F., Zamarian, L., Koppelstaetter, F., Siedentopf, C. M., Kaufmann, L., Benke, T. and Felber, S. 2005. Learning by strategies and learning by drillevidence from an fmri study. NeuroImage, 25(3), pp. 838-849.

Festini, S. B., Mcdonough, I. M. and Park, D. C. 2016. The busier the better: Greater busyness is associated with better cognition. Frontiers in Aging Neuroscience, 8(98).

World Economic Forum. 2020. Covid-19 - the true test of asean youth's, resilience and adaptability impact of social distancing on asean youth. ASEAN Youth Survey 2020 Edition July 2020. [PDF] World Economic Forum. Available at http://www3.weforum.org/docs/WEF_ASEAN_Youth_Survey_2020_Report.pdf [Acessed 15 August 2020].

Foubert-Samier, A., Catheline, G., Amieva, H., Dilharreguy, B., Helmer, C., Allard, M. and Dartigues, J.-F. 2010. Education, occupation, leisure activities, and brain reserve: A population-based study. Neurobiology of Aging, 33(2), pp. 423.e15-25.

Grisold, T. and Kaiser, A. 2017. Leaving behind what we are not: Applying a systems thinking perspective to present unlearning as an enabler for finding the best version of the self. Journal of Organisational Transformation \& Social Change, 14(1), pp. 39-55.

Hertzog, C. and Dunlosky, J. 2011. Metacognition in later adulthood: Spared monitoring can benefit older adults' self-regulation. Current Directions in Psychological Science, 20(3), pp. 167-173.

Howard-Jones, P. A. 2010. Introducing neuroeducational research: Neuroscience, education and the brain from contexts to practice, New York, Routledge.

Hutchins, E. 1995. Cognition in the wild, Cambridge, Massachusetts, The MIT Press. 
Science of Lifelong Learning

Jenkins, A. 2011. Participation in learning and wellbeing among older adults. International Journal of Lifelong Education, 30(3), pp. 403-420.

Jenkins, A. and Mostafa, T. 2015. The effects of learning on wellbeing for older adults in England. Ageing and Society, 35(10), pp. 2053-2070.

Josefsson, M., De Luna, X., Pudas, S., Nilsson, L. G. and Nyberg, L. 2012. Genetic and lifestyle predictors of 15-year longitudinal change in episodic memory. Journal of the American Geriatrics Society, 60(12), pp. 2308-2312.

Kennedy, K. M., Rodrigue, K. M., Bischof, G. N., Hebrank, A. C., Reuter-Lorenz, P. A. and Park, D. C. 2015. Age trajectories of functional activation under conditions of low and high processing demands: An adult lifespan fmri study of the aging brain. Neuroimage, 104, p. 2134.

Knowland, V. C. P. and Thomas, M. S. C. 2014. Educating the adult brain: How the neuroscience of learning can inform educational policy. International Review of Education 60(1), pp. 99-122.

Knowles, M. S. 1978. Andragogy: Adult learning theory in perspective. Community College Review, 5(3), pp. 9-20.

Knudsen, E. I. 2004. Sensitive periods in the development of the brain and behavior. Journal of Cognitive Neuroscience, 16(8), pp. 1412-1425.

Laal, M. and Salamati, P. 2012. Lifelong learning; why do we need it? Procedia - Social and Behavioral Sciences, 31, pp. 399-403. 
Science of Lifelong Learning

Larivière, S., Xifra-Porxas, A., Kassinopoulos, M., Niso, G., Baillet, S., Mitsis, G. D. and Boudrias, M.-H. 2019. Functional and effective reorganization of the aging brain during unimanual and bimanual hand movements. Human Brain Mapping, 40(10), pp. 3027-3040.

Lee, V. 2017. A short history of learning sciences. In: West, R. E. (ed), foundations of learning and instructional design technology ( $\left.1^{\text {st }} e d.\right)$. EdTech Books. Chapter 4.

Menon, V. 2010. Developmental cognitive neuroscience of arithmetic: Implications for learning and education. ZDM Mathematics Education, 42(6), pp. 515-525.

Nakanishi, M., Yamasaki, S., Nishida, A. and Richards, M. 2019. Midlife psychological wellbeing and its impact on cognitive functioning later in life: An observational study using a female British birth cohort. Journal of Alzheimer's disease 72(3), pp. 835-843.

Narushima, M., Liu, J. and Diestelkamp, N. 2018. Lifelong learning in active ageing discourse: It's conserving effect on wellbeing, health and vulnerability. Ageing and Society, 38(4), pp. 651-675.

Noah, J. A., Ono, Y., Nomoto, Y., Shimada, S., Tachibana, A., Zhang, X., Bronner, S. and Hirsch, J. 2015. Fmri validation of fnirs measurements during a naturalistic task. Journal of Visualized Experiments, (100), pp. e52116-e52116.

Park, D. and Gutchess, A. 2006. The cognitive neuroscience of aging and culture. Current Directions in Psychological Science, 15(3), pp. 105-108.

Park, D. C. 2019. Cognitive ability in old age is predetermined by age 20 y. Proceedings of the National Academy of Sciences, 116(6), pp. 1832. 
Science of Lifelong Learning

Park, D. C. and Bischof, G. N. 2011. Chapter 7 - neuroplasticity, aging, and cognitive function. In: Schaie, K.W \& Wills, S. L. (eds.) Handbook of the psychology of aging (seventh edition). San Diego, Academic Press, Chapter 7.

Park, D. C. and Bischof, G. N. 2013. The aging mind: Neuroplasticity in response to cognitive training. Dialogues in Clinical Neuroscience, 15(1), pp. 109-119.

Park, D. C. and Festini, S. B. 2017. The middle-aged brain: A cognitive neuroscience perspective. In Cabeza, R. Nyberg, L. \& Park, D. C. Cognitive neuroscience of aging: Linking cognitive and cerebral aging (2nd ed). New York, Oxford University Press. Chapter 14.

Park, D. C., Lodi-Smith, J., Drew, L., Haber, S., Hebrank, A., Bischof, G. N. and Aamodt, W. 2014. The impact of sustained engagement on cognitive function in older adults: The synapse project. Psychological Science, 25(1), pp. 103-112.

Pascual-Leone, A., Amedi, A., Fregni, F. and Merabet, L. B. 2005. The plastic human brain cortex. Annual Review of Neuroscience, 28, pp. 377-401.

Penhune, V. B. 2011. Sensitive periods in human development: Evidence from musical training. Cortex, 47(9), pp. 1126-37.

Pudas, S., Persson, J., Josefsson, M., De Luna, X., Nilsson, L.-G. and Nyberg, L. 2013. Brain characteristics of individuals resisting age-related cognitive decline over two decades. The Journal of Neuroscience, 33(20), pp. 8668-8677.

Ramscar, M., Hendrix, P., Shaoul, C., Milin, P. and Baayen, H. 2014. The myth of cognitive decline: Non-linear dynamics of lifelong learning. Topics in Cognitive Science, 6(1), pp. 542. 
Science of Lifelong Learning

Rasmussen, B. Sweeny, K. and Sheehan, P 2015. Cost of early retirement due to ill health:

Phase ii countries. Report to the APEC Business Advisory Council and US Chamber of

Commerce, VISES, Victoria Univesity, Melbourne, October. [PDF] Available at:

http://www.vises.org.au/documents/2015_Rasmussen_et_al_Cost_of_Early_Retirement_Phas

e_II.pdf. [Accessed 15 August 2020].

Reuter-Lorenz, P. A. and Park, D. C. 2014. How does it stac up? Revisiting the scaffolding theory of aging and cognition. Neuropsychology Review, 24(3), pp. 355-370.

Ritchie, K., Ritchie, C. W., Yaffe, K., Skoog, I. and Scarmeas, N. 2015. Is late-onset

Alzheimer's disease really a disease of midlife? Alzheimer's \& dementia, 1(2), pp. 122-130.

Rose, L. T., Rouhani, P. and Fischer, K. W. 2013. The science of the individual. Mind, Brain, and Education, 7(3), pp. 152-158.

Schlaggar, B. L. and Mccandliss, B. D. 2007. Development of neural systems for reading. Annual Review of Neuroscience, 30(1), pp. 475-503.

Schwartz, M. S., Hinesley, V., Chang, Z. and Dubinsky, J. M. 2019. Neuroscience knowledge enriches pedagogical choices. Teaching and Teacher Education, 83, pp. 87-98.

Serra, M. C., Dondero, K. R., Larkins, D., Burns, A. and Addison, O. 2020. Healthy lifestyle and cognition: Interaction between diet and physical activity. Current Nutrition Reports, 9(2), pp. 64-74.

Somerville, L. H. and Casey, B. J. 2010. Developmental neurobiology of cognitive control and motivational systems. Current Opinion in Neurobiology, 20(2), pp. 236-241. 
Science of Lifelong Learning

Steiner, G. 2001. Transfer of learning, cognitive psychology of. In: Smelser, N. J. \& Baltes,

P. B (eds.) International encyclopedia of the social \& behavioral sciences. Oxford, Pergamon.

Sweeny, K. Rasmaussen, B and Sheehan, P. 2015. The impact of health on worker attendance and productivity in twelve countries. Report to the APEC Business Advisory Council and US Chamber of Commerce, VISES, Victoria Universirt, Melbourne, October. [PDF] Available at: https://pdfs.semanticscholar.org/d674/efa417e7dd9df27c4d9e6f9f7fd910f28a2a.pdf?_ga=2.2 59598922.1387419713.1597486456-1187753797.1588937653 [Accessed 15 August 2020]. Tan, C. 2017. Lifelong learning through the skillsfuture movement in Singapore: Challenges and prospects. International Journal of Lifelong Education, 36(3), pp. 278-291.

Tan, S. C., Chen, S. H. A., Goodwill, A. M., Jamaludin, A. B., Walker, Z. and Hale, J. B. 2019. Developing a translating educational neuroscience clearinghouse for the differentiated instruction of diverse learners. NIE Research Brief Series No. 19-017. Singapore, National Institute of Education.

Teixeira-Santos, A. C., Moreira, C. S., Magalhães, R., Magalhães, C., Pereira, D. R., Leite, J., Carvalho, S. and Sampaio, A. 2019. Reviewing working memory training gains in healthy older adults: A meta-analytic review of transfer for cognitive outcomes. Neuroscience and Biobehavioral Reviews, 103pp. 163-177.

Tham, R., Walker, Z., Tan, S. H. D., Low, L. T. and Chen, A. S.-H. 2019. Translating education neuroscience for teachers. Learning: Research and Practice, 5(2), pp. 149-173.

Thow, M. E., Summers, M. J., Saunders, N. L., Summers, J. J., Ritchie, K. and Vickers, J. C. 2018. Further education improves cognitive reserve and triggers improvement in selective 
Science of Lifelong Learning

cognitive functions in older adults: The tasmanian healthy brain project. Alzheimer's \& Dementia: Diagnosis, Assessment \& Disease Monitoring, 10, pp. 22-30.

Ton, T. G. N., Deleire, T., May, S. G., Hou, N., Tebeka, M. G., Chen, E. and Chodosh, J. 2017. The financial burden and health care utilization patterns associated with amnestic mild cognitive impairment. Alzheimer's \& dementia, 13(3), pp. 217-224.

Verhaeghen, P. and Salthouse, T. A. 1997. Meta-analyses of age-cognition relations in adulthood: Estimates of linear and nonlinear age effects and structural models. Psychological Bulletin, 122(3), pp. 231-49.

Vogel, S. and Schwabe, L. 2016. Learning and memory under stress: Implications for the classroom. Npj Science of Learning, 1(1), pp. 16011.

Walker, Z., Chen, A. S. H., Poon, K. K. and Hale, J. B. 2017. Brain literacy empowers educators to meet diverse learner needs. NIE Working Paper Series No. 10. Singapore, National Institute of Education.

Yaffe, K., Fiocco, A. J., Lindquist, K., Vittinghoff, E., Simonsick, E. M., Newman, A. B., Satterfield, S., Rosano, C., Rubin, S. M., Ayonayon, H. N., Harris, T. B. and Health, A. B. C. S. 2009. Predictors of maintaining cognitive function in older adults: The health ABC study. Neurology, 72(23), pp. 2029-2035.

Yeo, R. 2008. How does learning (not) take place in problem-based learning activities in workplace contexts? Human Resource Development International, 11, pp. 317-330.

Yu, L., Shek, D. T. L. and Zhu, X. 2018. The influence of personal well-being on learning achievement in university students over time: Mediating or moderating effects of internal and external university engagement. Frontiers in Psychology, 8(2287). 
Science of Lifelong Learning 